\title{
Successful over-the-scope clip (OTSC) treatment for severe bleeding due to anastomotic dehiscence
}

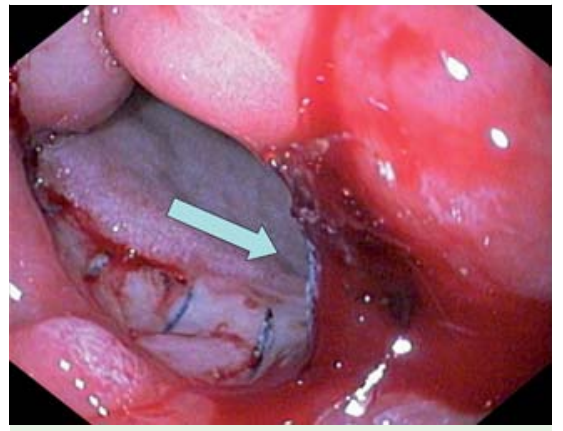

Fig. 1 Active oozing of blood (arrow) from a gastroenteral anastomotic dehiscence in a 71-year-old woman who had undergone laparotomic debridement with a Billroth I gastroenteral anastomosis 3 weeks previously.

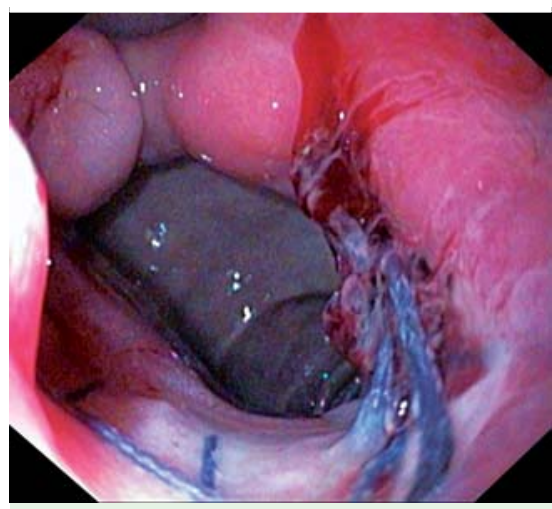

Fig. 3 Epinephrine (1:10000) injection for local vasoconstriction, volume tamponade, and facilitation of a clear view.

Postanastomotic complications of the gastrointestinal tract, including leakage and bleeding, are rare but critical conditions requiring prompt treatment. Most anastomotic problems are managed surgically [1], but endoscopic therapy is considered as the first choice of treatment for bleeding and treatment of an incomplete anastomotic dehiscence with no peritoneal involvement $[1,2]$.

Here we report the case of a 71-year-old woman presenting with an acute fall in hemoglobin level (11.7 to $9.1 \mathrm{~g} / \mathrm{dL}$ ), hypotension $(90 / 50 \mathrm{mmHg})$, and melena. Physical examination revealed skin pallor and tachycardia (130 beats per min). The patient had undergone laparotomic debridement with a Billroth I gastroenteral anastomosis 3 weeks before for an advanced ovarian tumor with massive peritoneal carcinomatosis. Emergent esophagogastroduodenoscopy (EGD) revealed oozing

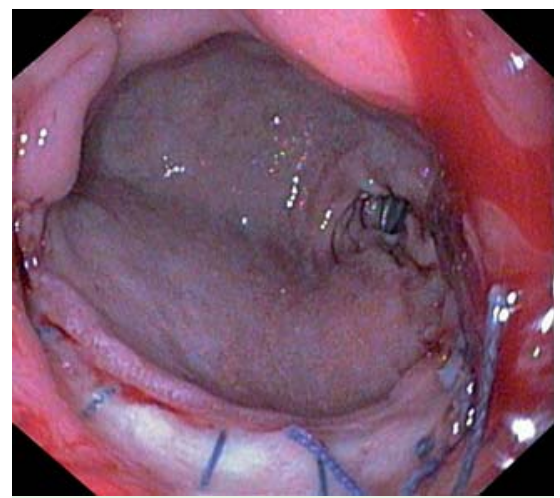

Fig. 2 Anastomotic dehiscence (diameter about $25 \mathrm{~mm}$ ) affecting the posterior wall.

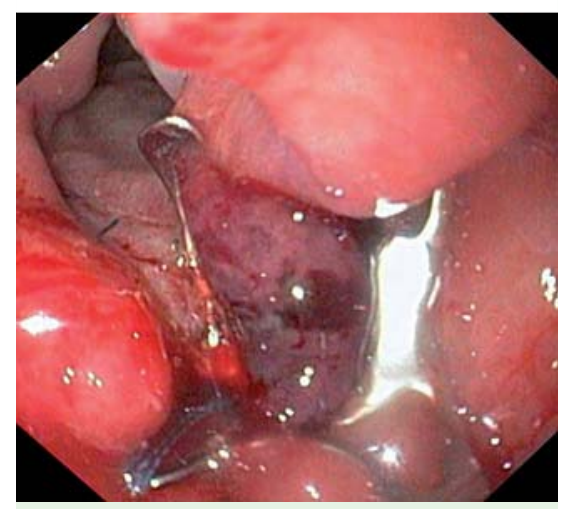

Fig. 4 Hemostasis and leak closure using the over-the-scope clip (OTSC) with blunt teeth.

bleeding from an anastomotic dehiscence at the posterior wall ( $\bullet$ Fig. 1). The dehiscence extended over half the circumference of the anastomosis, with a diameter of about $25 \mathrm{~mm}$ ( Fig.2). Based on the size and position of the leak, we decided to use an over-the-scope clip (OTSC) for sealing the dehiscence. The procedure commenced with injection of epinephrine $1: 10000$ to reduce the active bleeding ( $\bullet$ Fig. 3 ). Then scope was withdrawn and the "atraumatic" version of OTSC (with blunt teeth) was mounted on the tip as previously described $[2,3]$. Next, the Twin Grasper (Ovesco, Tübingen, Germany) was advanced through the working channel of the endoscope to access the leak margins. Maneuvering the tip of the scope with gentle axial rotation allowed placement of the OTSC correctly over the dehiscence. The Twin Grasper was pulled into the distal cap of the OTSC system under continuous suction. The OTSC was deployed after the clear distal cap was filled to more than half its volume with tissue. OTSC placement took about 2 minutes and the subsequent endoscopic examination revealed complete closure of the leak and stable hemostasis ( $\mathbf{~ F i g . 4 ) .}$ The patient's clinical condition stabilized and she was discharged 5 days later.

This case is interesting for several reasons. First, we have demonstrated how OTSC use can aid emergent endoscopic therapy when other hemostatic and leak sealing techniques are deemed unsuitable due to technical problems such as right target position in a 5 o'clock oriented working channel, large leak (10-25 mm), and massive bleeding [1-4]. Second, we have provided a detailed description of the procedure, which may assist further use of the technique. Third, we have shown successful use of the OTSC for treatment of a larger anastomotic leak [1,2]. Finally, our report adds to the growing literature on potential applications of the OTSC [15]. Altogether, the recently introduced OTSC system provides a practical solution to difficult endoscopic treatment where standard clipping techniques may not be appropriate. The OTSC should be considered as the first choice for sealing of intermediate leaks.

Endoscopy_UCTN_Code_TTT_1AO_2AD

Competing interests: None

G. E. Tontini ${ }^{1,2}$, A. Naegel ${ }^{1}$, H. Albrecht ${ }^{1}$, M. Vieth ${ }^{3}$, M. Vecchi' ${ }^{2,4}$, M. F. Neurath', H. Neumann ${ }^{1}$

${ }^{1}$ Department of Medicine I, University of Erlangen-Nuremberg, Germany

${ }^{2}$ Gastroenterology and Digestive Endoscopy Unit, IRCCS Policlinico San Donato, San Donato Milanese, Italy ${ }^{3}$ Institute of Pathology, Klinikum Bayreuth, Bayreuth, Germany

${ }^{4}$ Department of Medical Science for Health, University of Milan, Italy

\section{Acknowledgment $\nabla$}

G. E. Tontini has received a grant from the Italian Group for the study of inflammatory bowel disease (IG-IBD), supporting his research work at the Department of Medicine I, University of Erlangen-Nuremberg. 


\section{References}

1 Manta R, Magno L, Conigliaro $R$ et al. Endoscopic repair of post-surgical gastrointestinal complications. Dig Liver Dis

2 Manta R, Manno M, Bertani $\mathrm{H}$ et al. Endoscopic treatment of gastrointestinal fistulas using an over-the-scope clip (OTSC) device: case series from a tertiary referral center. Endoscopy 2011; 43: 545 - 548

3 Mönkemüller K, Toshniwal J, Zabielski M et al Utility of the "bear claw," or over-the-scope clip (OTSC) system, to provide endoscopic hemostasis for bleeding posterior duodenal ulcers. Endoscopy 2012; 44 (Suppl. 02): E412-413

4 Baron TH, Song LM, Ross A et al. Use of an over-the-scope clipping device: multicenter retrospective results of the first U.S. experience (with videos). Gastrointest Endosc 2012; 76: $202-208$

5 Naegel A, Bolz J, Zopf $Y$ et al. Hemodynamic efficacy of the over-the-scope clip in an established porcine cadaveric model for spurting bleeding. Gastrointest Endosc 2012; 75: $152-159$

\section{Bibliography}

Dol http://dx.doi.org/

10.1055/s-0033-1344771

Endoscopy 2013; 45: E343-E344

(c) Georg Thieme Verlag KG

Stuttgart · New York

ISSN 0013-726X

\section{Corresponding author}

\section{G. E. Tontini}

Department of Medicine I

University of Erlangen-Nuremberg

Ulmenweg 18

91054 Erlangen

Germany

Fax: +49-9131-8535209

gianeugeniotontini@gmail.com

gianeugeniotontini@libero.it 